\title{
A CENA FABULÍSTICA DE HERMÉS: UMA PERSPECTIVA SEMIÓTICA SOBRE AS NARRATIVAS DA MARCA
}

\section{The fabulistic scene of Hermés: a semiotic perspective on brand narratives}

\section{La escena fabulística de Hermés: una perspectiva semiótica en las narrativas de la marca}

\author{
Bruno Pompeu ${ }^{1}$ \\ Clotilde Perez ${ }^{2}$
}

\section{Resumo}

As marcas são, hoje, na vida cotidiana, um dos elementos mais repletos de significado e mais importantes socialmente. Isso porque nelas se alicerçam tanto a comunicação quanto o consumo - as marcas, por um lado, para funcionar como tal, precisam se expressar, precisam se comunicar, precisam criar vínculos; por outro, são quase sempre entidades que fomentam o consumo. Tendo esse panorama de fundo, o presente texto pretende analisar peças da campanha publicitária da marca Hermès, buscando verificar os sentidos que esta marca anunciante a si própria atribui por meio das estratégias narrativas e estéticas adotadas. Para tanto, busca-se o aporte teórico na semiótica de vertente greimasiana, para que, a partir dos três níveis do texto apresentados e desenvolvidos por seus principais autores, se possa analisar o universo semântico que a tal marca cria, sempre procurando estabelecer vínculos de afeto e instigação do desejo - como convém a uma marca. Adicionalmente integram-se à análise as contribuições das principais teorias do consumo contemporâneas, no sentido de explicitar a centralidade que as marcas assumiram exercendo sua função sígnica primordial de mediação.

\footnotetext{
${ }^{1}$ Doutorando em Ciências da Comunicação, pela Escola de Comunicações e Artes da Universidade de São Paulo (ECA-USP). Bolsista CAPES. Mestre pela mesma instituição. Publicitário, professor do Istituto Europeo di Design. Membro do GESC ${ }^{3}$ - Grupo de Estudos Semióticos em Comunicação, Cultura e Consumo.brupompeu@uol.com.br.

${ }^{2}$ Livre-docente em Ciências da Comunicação pela Escola de Comunicações e Artes da Universidade de São Paulo (ECA-USP). Doutora em Semiótica e Mestre em Marketing pela PUC-SP. Professora da ECA-USP. Professora da PUC SP. Vice líder do GESC ${ }^{3}$ - Grupo de Estudos de Semiótica, Comunicação, Cultura e Consumo.cloperez@terra.com.br.
} 
A cena fabulística de hermés: uma perspectiva semiótica sobre as narrativas da marca de Bruno Pompeu e Clotilde Perez

Palavras-chave: marca, publicidade, semiótica, Hermès, consumo, contos de fadas.

\begin{abstract}
The brands are now in everyday life, one of the most full of meaning and most important socially. This is because in them are founded on both communication and consumption the marks on the one hand, to act as such, need to express themselves, need to communicate, they need to create links, on the other hand, are almost always entities that encourage consumption. Having this background scenario, this article intends to analyze parts of the Hermès brand advertising campaign, seeking to verify the senses that this brand advertiser attaches itself by means of aesthetic and narrative strategies adopted. To this end, we seek to the theoretical slope Greimas in semiotics, so that, from the three levels of text presented and developed by its principal authors, one can analyze the semantic universe that creates such a mark, always seeking to establish links instigation of affection and desire - as befits a brand. In addition to the analysis integrate the contributions of the main contemporary theories of consumption, in order to explain the centrality assumed that brands exercising their fundamental semiotic mediation.
\end{abstract}

Keywords: brand, advertising, semiotics, Hermès, consumption, fairy tales.

\title{
Resumen
}

Las marcas se encuentran ahora en la vida cotidiana, una de las más llenas de significado y más importante socialmente. Esto es porque en ellas se basan la comunicación y el consumo - las marcas, por un lado, para actuar como tales, necesitan expresarse, necesitan comunicarse, necesitan crear vínculos, por el contrario, casi siempre son las entidades que fomentan el consumo. Tener este escenario de fondo, este artículo pretende analizar las piezas de la campaña de publicidad de La marca Hermès, tratar de verificar los sentidos que el anunciante de la marca se une a través de estrategias estéticas y narrativas adoptadas. Para ello, buscamos a los Greimas pendiente teórica de la semiótica, de modo que, a partir de los tres niveles de texto presentado y desarrollado por sus autores principales, se puede analizar el universo semántico que crea una marca, siempre tratando de establecer vínculos instigación de afecto y el deseo - como corresponde a una marca. Además del análisis de integrar las contribuciones de las principales teorías contemporáneas de consumo, con el fin 
A cena fabulística de hermés: uma perspectiva semiótica sobre as narrativas da marca de Bruno Pompeu e Clotilde Perez

de explicar la centralidad supone que las marcas de ejercer su mediación semiótica fundamental.

Palavras-clave: marca, la publicidad, la semiótica, Hermes, consumo, cuentos de hadas.

\section{INTRODUÇÃO}

Se a comunicação e o consumo assumem, hoje, uma centralidade inédita na vida cotidiana contemporânea - como afirmam Everardo Rocha (2006) e Gisela Taschner (2009), fazendo coro com outros tantos autores a serem citados adiante -, merece que se dê também destaque e atenção ao papel protagonista que as marcas vêm desempenhando nesse contexto. Possivelmente são elas o elemento que justamente faça o encadeamento e a mediação entre a comunicação e o consumo.

Porque as marcas têm, de um lado, as suas expressividades, suas formas de se apresentar; e têm, de outro, as suas ofertas, seus produtos e seus serviços. Ou seja: comunicação de um lado e consumo do outro, ainda que esta separação seja apenas didática, uma vez que a interação é a tônica desta dialogia. De modo que estudar marcas, hoje, é também estudar esses dois importantes temas postos em conexão.

E, dentre as estratégias de marca mais recorrentes e interessantes da atualidade, destacam-se aquelas relativas às narrativas, aquelas que envolvem a marca em um universo ficcional, repleto de possibilidades semânticas e estéticas, sempre pronto para enlaçar afetivamente o público e, a partir daí, criar significado e estabelecer vínculo emocional.

Este texto, então, propõe-se a estudar algumas manifestações concretas dessas estratégias de marca, ditas narrativas. Mais especificamente, o que se pretende aqui é uma análise semiótica de anúncios impressos da campanha da coleção primavera-verão de 2010 da marca de moda francesa Hermès. E vêm as perguntas: de que maneira as marcas têm agido no sentido de construir em torno de si narrativas efetivamente interessantes aos seus públicos? Que papel a marca anunciante assume dentro dessa narrativa e que possíveis significados isso pode gerar em seus públicos? Que estratégias estéticas vêm sendo empregadas pelas marcas anunciantes - e pelas agências de publicidade, claro - para transformar uma única imagem (estática, portanto) em um fragmento narrativo fértil de significado? 
A cena fabulística de hermés: uma perspectiva semiótica sobre as narrativas da marca de Bruno Pompeu e Clotilde Perez

Questões como essa o presente trabalho pretende, se não responder totalmente, ao menos discutir e propor encaminhamentos. Porque a já citada centralidade que o consumo e a comunicação ocupam hoje em dia faz com que seja impensável ou injustificável o desperdício de oportunidades como esta - este congresso, diga-se -, de se pensar acadêmica e tecnicamente as marcas em sua produção semântica.

Porque elas nos cercam, porque elas compõem o nosso cotidiano, porque elas são parte integrante da realidade a qual fazem remeter os signos por que somos impactados o tempo inteiro em todas as mídias e pontos de contato. E cabe justamente ao pesquisador do campo da Comunicação se debruçar sobre essas questões tão hodiernas quanto desafiadoras - isto por causa daquilo, talvez -, para que se possa evitar a superficialidade das conclusões diretas, o imediatismo dos raciocínios sem base, a ignorância, enfim. Para que se possa, também, compreender melhor, a partir do salutar exercício da reflexão acadêmica, as práticas cotidianas que nossos pares do mercado - às vezes nós mesmos, ou não? - estão empreendendo. Pensar nunca é demais.

\section{A SEMIÓTICA GREIMASIANA E A PUBLICIDADE}

Foi publicado em 1970 aquele que seria, depois, considerado o marco inicial das análises da publicidade com base em teorias da linguagem. O texto se chamava "Retórica da imagem” e, nele, seu autor, Roland Barthes (1990: 27-43), ousava aplicar conceitos desenvolvidos a partir da Linguística de Saussure a um anúncio publicitário. Analisando as possíveis relações entre a imagem de um anúncio com o seu respectivo texto, Barthes estabeleceu algumas categorias de imagens, algumas funções para o texto e, talvez sem imaginar que o fazia, inaugurou uma tradição que se alonga até os dias de hoje. Mas seu texto, conquanto brilhante, era ainda embrionário, como se pode notar:

Ao nivel da mensagem literal, a palavra responde, de maneira mais ou menos direta, mais ou menos parcial, à pergunta: o que é? (...) Ao nível da mensagem 'simbólica', a mensagem linguística orienta não mais a identificação, mas a interpretação, constitui uma espécie de barreira que impede a proliferação dos sentidos conotados, seja em direção a regiões demasiadamente individuais (isto é, limita o poder de projeção da imagem), seja em direção aos valores disfóricos. (BARTHES, 1990: 33) 
A cena fabulística de hermés: uma perspectiva semiótica sobre as narrativas da marca de Bruno Pompeu e Clotilde Perez

Quem deu importante contribuição para a avaliação e organização das várias possibilidades teóricas de análise da publicidade foram Sandra de Souza e Christiane Santarelli (2008: 133-156), em artigo que enfileira as principais vertentes, os marcos mais importantes e aponta os caminhos mais pisados. Embora as autoras refiram-se pouco às análises de propagandas feitas pela perspectiva da semiótica francesa - dita greimasiana por conta do seu autor fundante Algirdas Julien Greimas (1973) -, é possível localizar no esclarecedor artigo a vertente francesa da semiótica. Isso se dá quando elas abordam a obra de Jean Marie Floch:

O autor trouxe uma nova abordagem sobre estes estudos usando a semiótica greimasiana como instrumento de análise cujo interesse principal é a ideia de poder compreender os atos de linguagem. (...) O que Floch acrescenta de significante no estudo da linguagem é analisá-la seguindo os ensinamentos de Greimas e a teoria da significação gerativa de sentido (SOUZA; SANTARELLI, 2008: 146)

Como se pode perceber, ao citarem os avanços conseguidos por Jean Marie Floch no campo das análises da publicidade - e de outras manifestações mercadológicas, como fica sabendo quem lê a obra de Floch (1993) -, as autoras deixam evidente a filiação deste pesquisador aos ditames semióticos de Greimas e à sua Escola de Paris. Ditames estes que, no Brasil, foram abraçados por autores como Diana Luz Pessoa de Barros (2005), José Luiz Fiorin (1989), Eric Landowski \& Fiorin (1997), Ivan Lopes (2005) e Andrea Semprini (1992, 2006), que, uns mais outros menos, avançaram nos aspectos metódicos dessa teoria, permitindo a aproximação dela com as campanhas publicitárias.

Assim é que as análises adiante pretendem seguir estes trilhos acima apresentados: a vertente francesa da semiótica, partindo da sua estruturação fundamental e servindo-se também dos seus desdobramentos mais atuais. A ideia é percorrer os três níveis gerativos de sentido, desde o nível mais profundo (o fundamental), em que residiriam as oposições básicas em que as marcas anunciantes se sustentam; passando por um nível intermediário (o narrativo), por meio do qual seria possível compreender a função que a marca assume no interior do texto publicitário; até chegar ao nível mais superficial (o discursivo), em que se definem as localizações espaço-temporais da marca, bem como suas tematizações.

As peças publicitárias selecionadas são da marca de moda Hermès, fundada em 1837, que tem se mantido até hoje no mercado de alto-luxo como sólida referência de 
A cena fabulística de hermés: uma perspectiva semiótica sobre as narrativas da marca de Bruno Pompeu e Clotilde Perez

sofisticação, tradição e elegância (VILELA \& CASTAREDE, 2005), no entanto, ainda que alicerçada na permanência, os gestores da marca têm buscado nos últimos tempos novas possibilidades semânticas, quase sempre valendo-se de estratégias comunicacionais mais ousadas, menos literais, e também por meio de apelos ao lúdico, ao fantástico, ao mítico e ao fantasioso. É por isso que, para este texto, se escolheram peças publicitárias justamente desta marca: para verificar como as estratégias narrativas e estéticas empregadas nos anúncios selecionados podem contribuir para a construção dessas novas possibilidades de sentido.

As peças escolhidas fazem parte da campanha de lançamento da coleção primaveraverão de 2010 e foram veiculadas em revistas de moda de todo o mundo - inclusive o Brasil. As fotografias, absolutamente predominantes nos anúncios, são do fotografo italiano Paolo Roversi e comporão, como vai se ver, o centro das análises. Só que outro aspecto que, sem dúvida, contribuiu para a escolha de tal campanha foi o fato de ela se inspirar ainda que de maneira livre, sutil ou estilizada - em contos infantis. Porque foi precisamente dos contos infantis que brotaram os ensinamentos semióticos de Greimas.

É que, antes de Greimas, Vladimir Propp (2006) já tinha se preocupado com a estrutura da linguagem, tendo reunido para tanto mais de 400 contos populares russos chamados maravilhosos - e organizado, a partir desses contos, mais de 30 funções internas. Pelo ponto de vista teórico do autor, a forma com que se concatenassem essas funções seria a estrutura da narrativa. E Propp então percebeu que essas funções não eram exclusivas dos contos infantis russos, podendo ser encontradas (identificadas) em textos de todos os tipos. Greimas serviu-se dos pensamentos de Propp e essa interessante origem da semiótica é também o ponto de partida deste texto.

\section{A PRODUÇÃO DE SENTIDO DA MARCA}

Como se deparar com uma imagem que apresente uma escadaria, com sobre ela uma mulher descendo apressada e deixando para trás um dos pés dos seus sapatos, sem ser remetido imediatamente ao conto infantil da Cinderella - ou Gata Borralheira, como se dizia? Pois quem folheia uma Vogue ou uma Harper's Bazaar pode encontrar uma cena dessas em uma das páginas e vai estar diante de uma peça publicitária. Trata-se da 
A cena fabulística de hermés: uma perspectiva semiótica sobre as narrativas da marca de Bruno Pompeu e Clotilde Perez

campanha "La vie comme un conte" (A vida como um conto) (Figura 1), da marca Hermès, criada para divulgar sua coleção primavera-verão de 2010, cujo título, como se percebe, já indica o caminho estratégico - tanto temático quanto estético - adotado pela marca anunciante.

Fig. 1 - Campanha "La vie comme un conte"

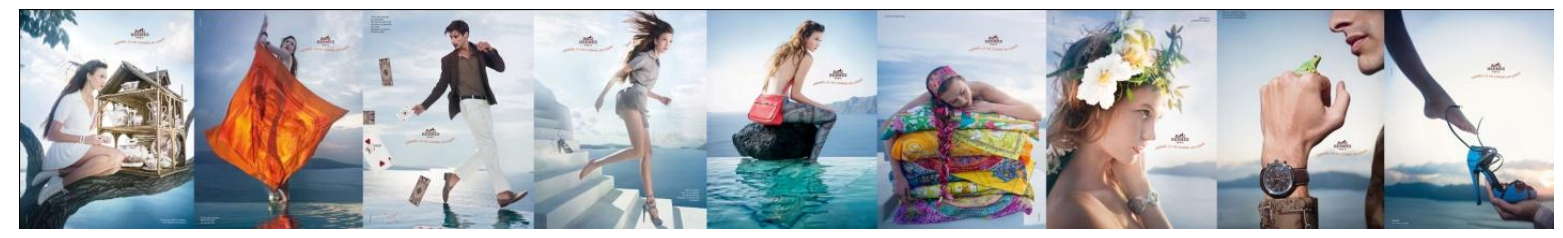

Dando início às análises pelo nível narrativo, como recomenda Barros (2005), podese, então, identificar nas peças publicitárias qual é a função actancial que os produtos e a marca anunciante, bem como os personagens e os demais elementos, representam no texto. No anúncio que faz referência à história "Rapunzel” (Figura 2), por exemplo, os produtos Hermès são os seus famosos lenços, que, no interior do texto, representam a torre que isola a personagem principal e a trança, talvez seu elemento mais importante e marcante.

Fig. 2 - Anúncio Rapunzel

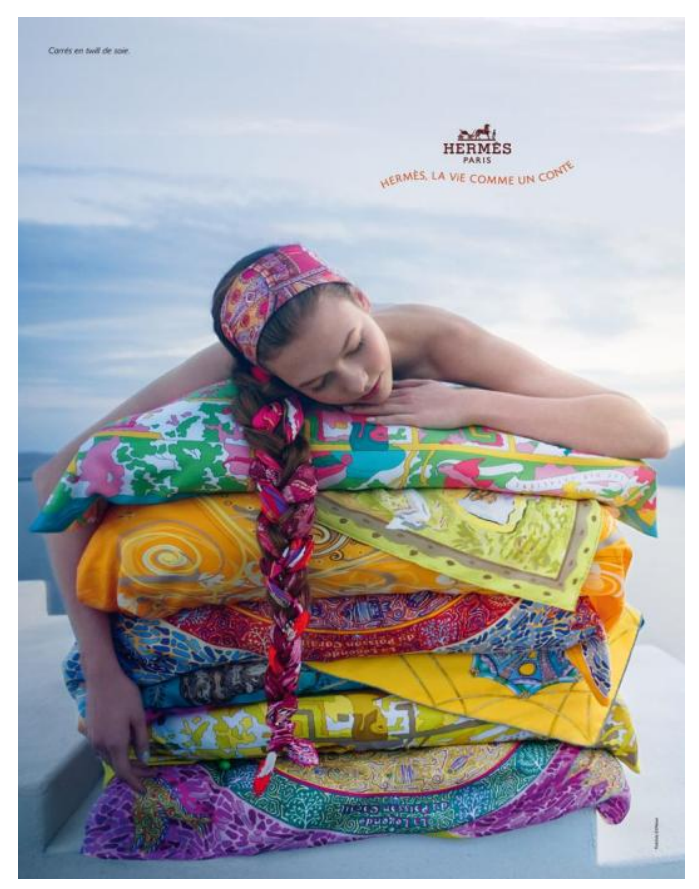


Como é de conhecimento geral, na história de Rapunzel, a menina é aprisionada por uma bruxa em uma torre e lá fica por anos, diariamente deixando que sua algoz a visite, subindo à torre pela trança de Rapunzel. Certa vez, um príncipe que passava pelo local se encanta com a voz da prisioneira e sobe para visitá-la (também valendo-se das longas melenas). Os encontros passam a ser diários e os dois passam a elaborar um plano de fuga para Rapunzel. Até que a bruxa descobre toda a situação, engana o príncipe e o atira do alto da torre ao espinheiro. Horrores se sucedem, mas o final feliz é garantido.

Como se pode ver, na peça, os produtos da marca anunciante tanto representam aquilo que afasta Rapunzel da vida comum (a torre), como também aquilo que dá às pessoas acesso à torre (a trança). Longe de querer aqui traçar uma análise semiótica completa e canônica, que procuraria dar conta de todos os esquemas, percursos e programas narrativos, cheios de detalhes e idas-e-vindas, quer-se, muito mais, usar a perspectiva greimasiana para que se evidenciem detalhes interessantes dos anúncios selecionados. Pois então, o que se pode inferir é que a mesma marca que afasta - que se faz elitista, que se mostra exclusiva, que se propõe inacessível, que é disjunção e disforia - é também a marca que dá acesso - que é possibilidade, que é escalada, que é amor, que é liberdade, que é, conjunção e euforia (BARROS, 2005: 19-24).

Tem-se aqui, então, um jogo interessante, pois bem revela a postura da marca Hermès (e de tantas outras do mesmo segmento), de ter que se equilibrar entre o aspiracional e o possível, entre o inacessível e o consumível, entre o inalcançável e o possível de se alcançar. O mercado do luxo vive constantemente a tensão entre a lógica artesanal e estética e a lógica industrial e financeira, o acaba por gerar luxos plurais (PEREZ, 2007). E, se no conto popularmente conhecido, a história se desenvolve sobre a oposição liberdade vs. aprisionamento, pode-se dizer que, dentro do texto apresentado pela peça publicitária, a oposição que define o nível fundamental é a do distanciamento vs. acesso.

Em outra peça da mesma campanha, a referência é o conto "Aladim e a lâmpada maravilhosa" (Figura 3). Nesse conto, a lâmpada, sendo friccionada, faz com que de dentro dela saia um gênio, disposto a satisfazer desejos os mais delirantes daquele que o libertou, chamado de amo. Ou seja: o objeto de valor é a lâmpada, é claro, mas não como um fim em 
si mesmo, e, sim, como possibilidade de realização de outros desejos. Na peça selecionada, pode-se ver uma lâmpada (ainda que estilizada), de onde sai um dos famosos lenços Hermès. Donde a relação comparativa é das mais óbvias: a marca ocupa, aqui, o lugar do gênio, não sendo, portanto, um fim em si - ainda que plenamente desejada, mágica, sedutora e misteriosa. A marca é, muito mais, o meio para conquistas muito maiores e mais impressionantes. Se Aladim, por meio do gênio, consegue fortunas, palácios e caravanas inteiras, o que pode conquistar um consumidor que tenha um lenço Hermès?

Fig. 3 - Anúncio Aladim

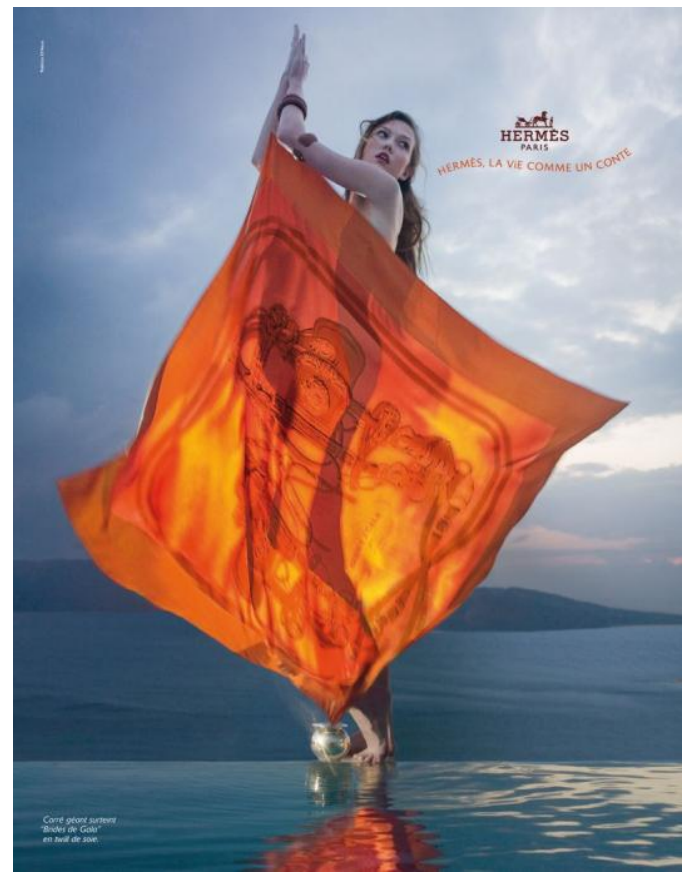

Para que não se distancie tanto dos ditames semióticos, pode-se dizer que, tanto na história popular quanto no anúncio, o gênio e a marca, respectiva e analogamente, representam modalizadores do fazer atualizantes, que qualificam o sujeito para a ação (BARROS, 2005: 43-45). É bem verdade que ainda seria possível dizer que a marca manipula o sujeito-consumidor (representado no anúncio pela modelo) por sedução e que haveria nisso uma modalização virtualizante, que instauraria o tal sujeito na cena.

A história de Aladim está possivelmente estruturada sobre a oposição fundamental da pobreza vs. riqueza, sendo aquela associada a privações, sofrimentos e solidão, enquanto esta, a fartura, deleite e amor. Será que Hermès não se serve exatamente dos mesmos 
valores? Não tendo um lenço da tal marca, a vida é pobre, sem alegrias, vadia; de posse de um lenço Hermès, a pessoa tem acesso à fortuna, ao afeto, ao sucesso e à abundância.

Mais romântico, porém não menos ilusório, é o terceiro anúncio selecionado para este texto, referindo-se àquele que talvez seja o mais clássico dos contos (de fadas): “Cinderela". Na peça (Figura 4) - providencialmente metonímica -, pode-se ver um dos pés de uma mulher na iminência de ser calçado por um sapato Hermès, trazido este pelas mãos de um homem. No conto popular, este momento do calçamento do sapato representa exatamente o gáudio da menina pobre e enxovalhada, que passa simples e instantaneamente à condição de princesa (mudança de estado), deixando para trás as amarguras causadas por uma madrasta irascível, as agruras provocadas por irmãs desplantadoras, e a vida dura de humilhantes trabalhos domésticos.

Fig. 4 - Anúncio Cinderela

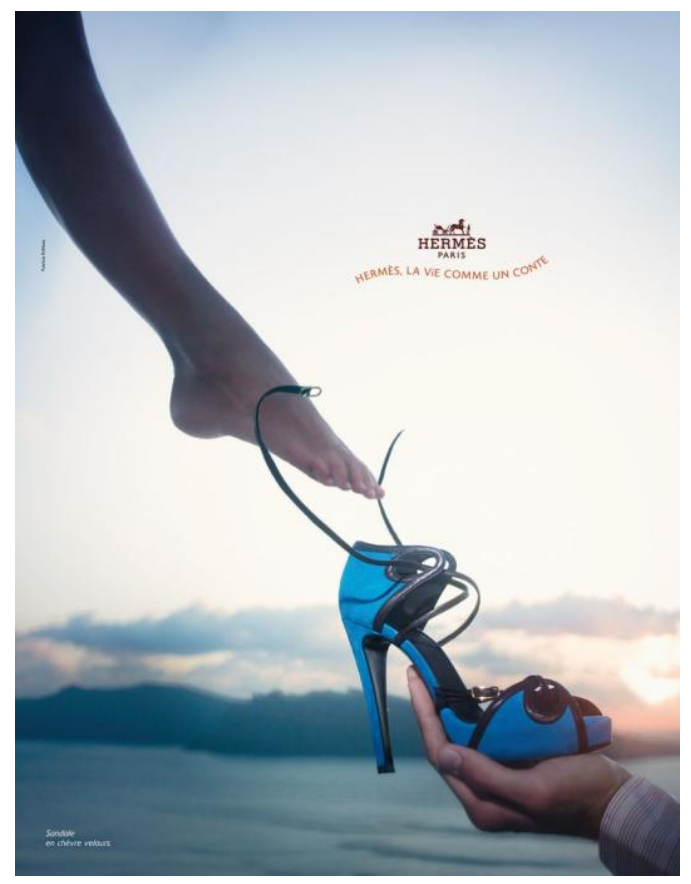

Usando, mais uma vez, os ensinamentos da semiótica greimasiana, pode-se dizer que o sapato, em "Cinderela", representa uma mudança de modalidade veridictória (BARROS, 2005: 45-46), fazendo com que se revele da personagem central um importante segredo: ela é a moça que o príncipe procura - mas não parece. E o fato de o sapato lhe calçar perfeitamente faz com que ela entre em conjunção com os valores eufóricos 
A cena fabulística de hermés: uma perspectiva semiótica sobre as narrativas da marca de Bruno Pompeu e Clotilde Perez

atrelados ao príncipe: amor, liberdade, felicidade, riqueza etc. A peça publicitária - talvez a mais literal das três escolhidas - representa apenas este momento de descoberta, em que a borralheira se revela a mulher buscada pelo príncipe. Só que isso não é pouco, como se pode notar: no anúncio, é a marca Hermès que permite à mulher entrar em conjunção com os seus valores positivos, tais como o amor, a conquista, a realização, a felicidade, o reconhecimento etc. E o fato de o sapato, no anúncio, estar sendo carregado pelas mãos de um homem - não por acaso sendo possível ver o punho da sua camisa social - só reforça esses sentidos buscados pela marca. É como se a Hermès propusesse às suas consumidoras a ideia de que, com seus produtos - com a marca, portanto -, a mulher tem acesso ao homem, mas sempre de forma romântica, idealizada, fantasiosa... fabulística.

No conto, a oposição fundamental pode ser a do sofrimento vs. casamento - por menos opostos que esses termos sejam de fato -, estando junto com o primeiro também a humilhação, a pobreza, o aprisionamento, mas também a solidão e, com o segundo, a riqueza, o amor, a felicidade e o encontro. Hermès, então, se vale de tudo isso e estrutura a sua narrativa publicitária sobre oposição análoga, deixando implícito que a marca tanto pode ser meio de acesso ao amor, à felicidade e à conquista do homem amado, quanto elemento revelador da princesa que a consumidora pode ser.

Deixou-se para este ponto a análise do nível discursivo porque, de certa forma, ele é recorrente na campanha como um todo. O "preenchimento semântico" (BARROS, 2005: 70) que as peças publicitárias explicitam é semelhante em todas elas e, juntas, elas estabelecem, portanto, uma figurativização única. Longe de localizar suas cenas fabulísticas em cenários tradicionalmente associados aos contos de fadas - castelos, florestas, reinos, bosques etc. -, os anúncios, ao contrário, apresentam as narrativas em locais radicalmente estilizados. E fica justamente por conta desse preenchimento semântico a vinculação da campanha com o universo fashion. Porque a estetização das peças - sustentada praticamente na direção de arte da fotografia e na produção de moda - traz os temas dos citados contos de fadas e suas respectivas estruturas narrativas para o universo tradicionalmente minimalista, elegante, sofisticado e idealizado da moda.

É possível notar também na figurativização das peças o fato de se tratar de uma coleção de primavera-verão, como já dito acima. É que a ambiência ao ar livre, o momento ensolarado e a consequente iluminação vibrante das fotografias remetem inevitavelmente a 
A cena fabulística de hermés: uma perspectiva semiótica sobre as narrativas da marca de Bruno Pompeu e Clotilde Perez

esse universo aquecido e diurno, típico dessas estações. A presença de um calmo mar esverdeado, sob um céu invariavelmente limpo e azulado, sem quase nenhum outro elemento cenográfico ou de composição cênica, fazem com que se possa pensar, ainda, em um tom mediterrâneo para a campanha, no que ela ganharia mais alguns toques de sofisticação, aquecimento, apelo ao ar livre, ancestralidade, ludicidade e idilismo.

A juventude e a feminilidade são outros aspectos que se pode perceber nos anúncios. Isso, claro, por conta da modelo selecionada para figurar em todas as fotografias. Sem embargo de o fato de se tratar de uma modelo mundialmente famosa, Karlie Kloss, gerar evidentemente outros potenciais efeitos de sentido, a pouca idade e os traços delicados da figura trazem para a campanha fortes marcas de juventude, idealização e inocência. Nesse sentido, Lipovetsky afirma que a moda - mas não apenas ela - busca o ideal da juventude:

Na origem do inconspicuous consumption, a ação convergente de um feixe de valores onde figuram o ideal igualitário, a arte moderna, os valores esportivos e, mais perto de nós, o novo ideal individualista do look jovem (LIPOVETSKY, 1989: 119).

Ou seja: é no nível discursivo, por meio das estratégias de figurativização, que a campanha se define como sendo de moda, como sendo de luxo, como sendo de primaveraverão, como sendo sofisticada, idealista, lúdica etc.

\section{REFLEXÕES À LUZ DO CONSUMO}

Os anúncios selecionados para este texto, assim como todos os outros que fazem parte da mesma campanha, são quase que exclusivamente figurativos, trazendo como elemento textual apenas o nome da marca e o título da campanha, "Hermès. La vie comme un conte”. Quando muito, há um discretíssimo e minúsculo texto (tanto em extensão quanto em tamanho de letra) enumerando os artigos de moda usados na fotografia. Não há texto publicitário que faça referências a preço, a pontos de venda, a atributos, benefícios. Não há apelos, chamadas, slogans, assinaturas, nada. Mas não há quem se depare com uma das tais

peças e não perceba instantaneamente que se trata de um anúncio publicitário. É que o contexto atual em que se vive faz com que seja assim, conforme ensina Zygmunt Bauman: “A 'sociedade de consumidores' é um tipo de sociedade que 'interpela' seus membros 
A cena fabulística de hermés: uma perspectiva semiótica sobre as narrativas da marca de Bruno Pompeu e Clotilde Perez

basicamente na condição de consumidores” (2008: 70-71). Livia Barbosa, referindo-se ao pensamento de Don Slater, corrobora: "No mundo moderno o consumo se tornou o foco central da vida social" (2010: 32). Eis que, na condição constante, eterna e única de consumidor, tudo o que é emitido ao indivíduo contemporâneo nesse tipo de sociedade é para consumir, é publicidade.

E a publicidade, de acordo com os petardos de Jean Baudrillard, "não nos ilude: encontra-se para lá do verdadeiro e do falso, como também a moda está para lá do feio e do belo ou como o objeto moderno, na sua função de signo, se situa para lá do útil e do inútil" (2007: 166). Se não é isso mesmo o que se pode notar nos anúncios acima analisados? O estratagema da cena fabulística joga para longe a possibilidade de se pensar na publicidade - e nos objetos que ela anuncia, claro - como algo verdadeiro ou falso. Fica-se com o fantástico. E os produtos apresentados nas peças (que nem como tal são mostrados) passam longe da questão beleza ou fealdade, valendo muito mais como possibilidade de significado, como signo. Signo para consumir e, então, para ser consumido:

Os membros da sociedade de consumidores são eles próprios mercadorias de consumo, e é a qualidade de ser uma mercadoria de consumo que os torna membros autênticos dessa sociedade. Tornar-se e continuar sendo uma mercadoria vendável é o mais poderoso motivo de preocupação do consumidor, mesmo que em geral latente e quase nunca consciente. É por seu poder de aumentar o preço de mercado do consumidor que se costuma avaliar a atratividade dos bens de consumo. (BAUMAN, 2008: 76)

Por isso, então, é que os lenços e os sapatos anunciados na campanha acima adquirem tal valor: porque fazem daqueles que os consomem mercadorias mais valorizadas socialmente. Calce um sapato Hermès e encontre seu príncipe encantado - não pelo sapato, mas pela princesa que você é. Enrole-se num lenço Hermès e tenha seus desejos realizados - não pela compra do lenço, mas por tudo aquilo que ele pode lhe proporcionar. É a publicidade dando sentido ao consumo, preenchendo de significado o cotidiano, tal e qual afirma Everardo Rocha (2006: 12-13) nessa mesma linha de raciocínio - mas por uma outra perspectiva, menos crítica e sociológica, agora, sim, mais interpretativa e antropológica -, dando sequência ao pensamento de Mary Douglas e Baron Isherwood.

Os bens são acessórios rituais; o consumo é um processo ritual cuja função primária é dar sentido ao fluxo incompleto dos acontecimentos. (...) Os bens são, portanto, a parte visível da cultura. São arranjados em perspectivas e hierarquias que podem dar espaço para a 
A cena fabulística de hermés: uma perspectiva semiótica sobre as narrativas da marca de Bruno Pompeu e Clotilde Perez

variedade total de discriminações de que a mente humana é capaz. (...) O consumo usa os bens para tornar firme e visivel um conjunto particular de julgamentos nos processos fluidos de classificar pessoas e eventos. (DOUGLAS \& ISHERWOOD, 2009: 112-115)

Donde se pode dizer que a publicidade lida diretamente com os rituais do cotidiano: "A publicidade atua como potente método de transferência de significado, fundindo um bem de consumo a uma representação do mundo culturalmente constituído dentro dos moldes de um anúncio específico" (MCCRACKEN, 2003: 106). O que acontece nos anúncios analisados é precisamente isso, essa transferência de significado dos contos infantis para a marca anunciante, preenchendo os lenços, os sapatos, os relógios, as joias, as bolsas e as roupas de significados tradicional e culturalmente construídos. É assim que a marca se torna ao mesmo tempo lúdica e ancestral, romântica e idealista, delicada e atemporal, buscando vencer um dos desafios que hoje se lhe impõem, que é equilibrar-se entre o perene e o contemporâneo, de acordo com o que ensina Clotilde Perez (2007), no que poderia ser complementada por Grant McCracken: “Através do anúncio, bens antigos e novos estão constantemente destituindo-se de velhos significados e assimilando outros. Nesta medida, a propaganda funciona como um léxico dos significados culturais correntes" (2003: 109).

E o indivíduo, devidamente condicionado a funcionar ininterruptamente como consumidor, vale-se desse léxico para dar forma à sua identidade, que, conforme diz Néstor García Canclini (2010: 129)., "é uma construção que se narra” Assim, vai consumindo e, justamente por meio daquilo que consome, constrói sua identidade, a um só tempo massificada - já que a produção é industrial, geral e opressiva - e única - porque criada em mosaicos, combinações e arranjos. O consumo, portanto, é, hoje, o que molda a identidade das pessoas e isso faz com que seja inegável o que Mike Featherstone afirmou: "o mundo das mercadorias e os seus princípios estruturais são centrais para o entendimento da sociedade contemporânea" (1995: 123).

\section{CONSIDERAÇÕES FINAIS}

O que se buscou aqui, com as análises expressas no texto, foi uma aproximação entre as teorias do consumo - que, por menos consensuais que sejam, ganham inegáveis notoriedade e relevância - e a semiótica, já que o significado das coisas parece ser um 
A cena fabulística de hermés: uma perspectiva semiótica sobre as narrativas da marca de Bruno Pompeu e Clotilde Perez

elemento comum às duas áreas. Assim, para que se possa compreender melhor os mecanismos de que os gestores das marcas lançam mão para criar vínculos de sentido com seus consumidores por meio de sua publicidade, o uso da semiótica é muito profícuo.

No caso específico de Hermès, na campanha analisada, as estratégias são as mais interessantes. Porque a marca se situa indubitavelmente no confortável e irresistível terreno eufórico do sucesso, da conquista, do amor, da realização, da riqueza e da fartura, valendose das suas respectivas oposições - o fracasso, a derrota, a solidão, o aprisionamento, a pobreza, a privação - para deixar isso mais evidente e intenso. É o nível fundamental, que, embora sutilmente remodelado de anúncio para anúncio, permanece constante na campanha como um todo. É aquilo de que fala a marca, é aquilo que a marca oferece.

Entretanto, o que varia consideravelmente de uma peça para a outra é a função actancial que ela ocupa (por meio de seus produtos, claro), oscilando providencialmente entre sujeitos que são e que fazem, entre objetos que encarnam valores e que modificam sujeitos, entre modalizações, revelações, tentações, seduções etc. É o nível narrativo, em que a marca apresenta o tipo de vínculo que vai estabelecer com seus consumidores: vai seduzi-lo, vai tentá-lo, vai alterá-lo, vai transformá-lo, vai revelá-lo, vai...

E, por fim, o que faz da Hermès uma marca contemporânea - sem que nunca se deixe de lado seu aspecto histórico, clássico, perene e atemporal, claro - são as figurativizações: a localização tempo-espacial das peças, a direção de arte, a produção de moda, o tratamento cromático, a seleção dos modelos etc. É aqui, no nível discursivo, que entra o estilo da coleção, o aspecto necessariamente cambiante da moda. O jogo entre perenidade e mutação é muito bem construído, como pôde ser observado nas análises da campanha da marca.

Mas, cuidado. Porque "a moda é arbitrária, móvel e cíclica, nada acrescentando às qualidades intrínsecas do indivíduo. Possui, no entanto, o caráter de profundo constrangimento e o seu critério é o sucesso ou a relegação social" (BAUDRILLARD, 2007: 125). Advertência feita.

\section{REFERÊNCIAS BIBLIOGRÁFICAS}

BARBOSA, Livia. Sociedade de consumo. 3. ed. Rio de Janeiro: Zahar, 2010. 
A cena fabulística de hermés: uma perspectiva semiótica sobre as narrativas da marca de Bruno Pompeu e Clotilde Perez

BARROS, Diana L. P. de. Teoria semiótica do texto. 4. ed. São Paulo: Ática, 2005.

BARTHES, Roland. A retórica da imagem. In: BARTHES, Roland. O óbvio e o obtuso: ensaios críticos III. Rio de Janeiro: Nova Fronteira, 1990.

BAUDRILLARD, Jean. A sociedade de consumo. 3. ed. Lisboa: Edições 70, 2008.

BAUMAN, Zygmunt. Vida para consumo: a transformação das pessoas em mercadoria. Rio de Janeiro: Zahar, 2008.

CANCLINI, Néstor García. Consumidores e cidadãos: conflitos multiculturais da globalização. Rio de Janeiro: UFRJ, 2010.

DOUGLAS, Mary; ISHERWOOD, Baron. O mundo dos bens: para uma antropologia do consumo. Rio de Janeiro: UFRJ, 2009.

FEATHERSTONE, Mike. Cultura de consumo e pós-modernismo. São Paulo: Studio Nobel, 1995.

FIROIN, José Luiz. Elementos de análise do discurso. São Paulo: Contexto, 1989.

FLOCH, Jean-Marie. Semiotica, marketing y comunicación: bajo los signos, las estratégias. Buenos Aires: Paidós, 1993.

GREIMAS, Algirdas. Semântica estrutural: pesquisa de método. São Paulo: Cultrix, 1973. . Sobre o sentido: ensaios semióticos. Petrópolis: Vozes, 1975.

HELLIN, Pedro ; PEREZ, Clotilde. Valores corporativos na publicidade contemporânea. Pensamento \& Realidade, v. 24: 33-50, 2009.

LANDOWSKI, Eric \& FIORIN, José Luiz. O gosto da gente, o gosto das coisas: abordagem semiótica. São Paulo: Educ, 1997

LIPOVETSKY, Gilles. O Império do efêmero. São Paulo: Cia das Letras, 1989.

LOPES, Ivan C.; HERNANDES, Nilton. Semiótica: objetos e práticas. São Paulo: Contexto, 2005.

MCCRACKEN, Grant. Cultura e consumo: novas abordagens ao caráter simbólico dos bens e das atividades de consumo. Rio de Janeiro: MAUAD, 2003.

PEREZ, Clotilde. Universo sígnico do consumo: o sentido das marcas. Tese de Livredocência. São Paulo: ECA/USP, 2007

- Signos da marca: expressividade e sensorialidade. São Paulo: ThomsonLearning, 2004

PROPP, Vladimir. Morfologia do conto maravilhoso. São Paulo: Forense, 2006. 
A cena fabulística de hermés: uma perspectiva semiótica sobre as narrativas da marca de Bruno Pompeu e Clotilde Perez

ROCHA, Everardo. Representações do consumo: estudos sobre a narrativa publicitária. Rio de Janeiro: MAUAD, 2006.

SEMPRINI, Andrea. Le marketing de la marque: approche sémiotique. Paris: Liasons, 1993 . A marca pós-moderna. São Paulo: Estação das Letras, 2006

SOUZA, Sandra; SANTARELLI, Christiane. Contribuições para uma história da análise da imagem no anúncio publicitário. Revista Brasileira de Ciências da Comunicação. São Paulo, v. 31, n. 1: 133-156, jan./jul. 2008.

TASCHNER, Gisela. Cultura, consumo e cidadania. Bauru: Edusc, 2009

Artigo submetido: 03/2012

Artigo aprovado: 05/2012 